\title{
REPORTAJE
}

\section{Un recorrido por la historia de las migraciones en El Salvador}

\author{
A journey throughout the history of migrations in El Salvador
}

\section{Resumen}

El Museo Universitario de Antropología (MUA), de la Universidad Tecnológica de El Salvador (Utec), inauguró en el 2008 la "Sala de las Migraciones", con lo que busca visualizar, a través de un área permanente, el fenómeno de las migraciones en el país y el mundo. Leonardo Regalado es el museógrafo del MUA y uno de los creadores de la sala. Con breves remembranzas que expresó a revista entorno-relata cómo nació esta exposición, cuál es su contenido y qué legado deja para tener presente el tema.
Inés Ramírez de Clará Jefa de Publicaciones de la Utec

ines.ramirez@utec.edu.sv
"Quien tuvo la idea de hacer una exposición permanente sobre el fenómeno migratorio en El Salvador fue el doctor Ramón Rivas. A unos tres meses de haber abierto el museo, él ya tenía la idea de que había que instalarse una exhibición del fenómeno migratorio. Esto también porque dentro de las fases de diseño y montaje de la museografía del MUA habían quedado ciertas áreas sin tocar" —explica Regalado.

Fue en septiembre de 2006 cuando Rivas, antropólogo y en ese momento director del MUA de la Utec reunió a los arquitectos Eduardo Góchez, Óscar Batres y a

\section{Abstract}

The Museo Universitario de Antropología (MUA, given its Spanishacronym for UniversityMuseum of Anthropology), inaugurated its "Hall of Migrations" in 2008 with the purpose of displaying the phenomenon of migrations in the country and overseas with a permanent exhibition. Leonardo Regalado is the MUA's museum expert and one of the creators of this hall. Through a series of brief memories, he told Entorno how this exhibition was born, what its content is, and what its legacy is in order to keep the topic in mind.

Leonardo Regalado para discutir ideas sobre el montaje de una sala de exposición que contuviera la historia de los migrantes.

Prácticamente, lo primero que hizo Rivas fue volver a llamar al equipo que había diseñado el museo; y este equipo comenzó a darse a la tarea de buscar los posibles temas que conformaran la exhibición. Se dispuso que por cada sala sería un tema el que se abordaría, por lo cual la exposición tiene cuatro momentos: dos salas se basan en la historia de las migraciones y dos en 
los acontecimientos actuales. "No podemos hablar de las migraciones actuales sin entender las antiguas migraciones, sin entender que la población del continente americano ha sido formada a puras migraciones", cuenta Regalado que Rivas les decía.

El antropólogo comenzó a hacer una gestión en el ámbito interinstitucional con el gobierno de Japón para adquirir una donación, es decir, que ellos costearan una parte de la museografía previo al diseño de la exhibición. Es por ese medio como se consiguieron 74 mil dólares para cubrir los gastos de construcción de mobiliario y producción gráfica; el resto de la exhibición, incluyendo accesorios y luminarias, los costeó la universidad. "Contamos con la ayuda de un coleccionista, don José Luis Cabrera. Él es una de las personas que más nos han prestado colecciones para las exposiciones, ya sean temporales o permanentes" -expresa el museógrafo.

“Queríamos impactar, así que nos tomamos la sala completa. Queríamos que esto fuera un mapa y que la gente caminara por él. Luego ideamos una tarima para que la gente tuviera un referente de lo que son las migraciones actuales; es un mapa demostrativo" — relaciona el experto-. Y es que en la "Sala de las Migraciones", desde la luz, los colores, las fotografías se pretenden recrear los momentos históricos, para que el visitante entienda la agudeza y larga trayectoria del fenómeno. Como en el caso de la erupción del volcán de Ilopango, que, de acuerdo con las investigaciones arqueológicas, fue el causante de grandes migraciones, ya que hizo inhabitable muchas zonas del país.

"Es necesario dejar claro que los movimientos migratorios se deben a tres factores: desastres sociales, desastres naturales ecológicos y por las transacciones del comercio o la economía. Necesitábamos decir, también, que las migraciones hicieron que los grupos humanos se mezclaran entre sí y de allí surgieron nuevos grupos", afirma Regalado al hacer el recorrido en las dos primeras salas de museo.

Al llegar a la tercera sala, en una reseña se lee lo siguiente: "Después de haber recorrido un estimado de tres mil kilómetros el agotamiento por la caminata, frío, inseguridad, extravío, hambre y otras dejaciones, el inmigrante hispano debe enfrentar a una sociedad que lo margina por su origen y condición social, sin embargo, las comunidades latinas consolidan cada vez más su presencia en una sociedad con idioma y costumbres diferentes. Lo anterior ha propiciado una nueva cultura que revalora los símbolos identitarios que hacen desaparecer imaginariamente la frontera, estrechando y fortaleciendo los vínculos para legitimar sus derechos en la búsqueda de nuevas oportunidades de desarrollo para los inmigrantes latinoamericanos". "Este es un texto que escribió el equipo de museógrafos para la dicha sala" aclara Regalado.

La sala expone una amplia colección fotográfica de personas en la "Ruta del Migrante". Regalado recuerda que otra parte de la gestión de Rivas fue lograr la colaboración de El Diario de Hoy para obtener las suficientes fotografías; y se utilizaron frases extraídas de textos poéticos, como el "Poema de amor" de Roque Dalton, para dramatizar la realidad que reflejan las imágenes.

En la cuarta y última sala está ubicada una vitrina que tiene diversos objetos, como camándulas, pastillas, botellas de agua, fotografías, zapatos, papeles con direcciones, etc., que son de los que van abandonando los migrantes a través grandes áreas del inhóspito desierto. "Carmen Molina, antropóloga graduada de la Utec, nos ayudó a obtenerlos (Ios objetos); y la licenciada Rita Araujo nos apoyó, desde entonces, con los collages de fotografías que tiene la Sala" —dice Leonardo. Algo que no puede pasar desapercibido es que la tierra donde se encuentran estos objetos es del desierto de Yuma, en Estados Unidos, lugar por el que transitan los migrantes arriesgando sus vidas.

En la cuarta y última sala, Rivas consideró que dentro de los temas debería estar presente también la cambiante historia de la moneda del país. Tanto porque la economía ya no estaba sustentada en la exportación del café sino en las remesas y por la llegada de la dolarización, el colón pasó a ser parte del recuerdo, por lo cual esta es una de las vitrinas más visitadas por la población, en gran parte por generaciones que ya no tuvieron la oportunidad de conocer la anterior moneda nacional. 
Regalado cuenta que algunas de las personas que visitan la Sala hasta lloran al ver las fotografías, pues tienen familiares en Estados Unidos y para ellas es impactante ver parte de la realidad que estas personas viven al recorrer el difícil camino hacia ese país. "Hemos tenido visitas de personas que quedan impactadas. Viene con una idea y se van con otra. Por ejemplo, han venido estadounidenses que al terminar el recorrido se ven bastante reflexivos" - comenta Regalado.

Y no es para menos. El último pasillo del recorrido incluye una recreación de los rieles de "la Bestia", tren que muchos migrantes usan para cruzar México en su peligroso intento por llegar a suelo estadounidense. La idea original - comparte Leonardo- era poner una fotografía en el piso que simulara las vías del tren, pero Rivas pensó que era mejor instalar rieles verdaderos; y para seguridad de los visitantes, se les colocó encima una plataforma de vidrio que resiste pasar caminando sobre ella, teniendo la breve sensación de que se va en la línea del ferrocarril. "Mucha gente siente miedo al cruzar el vidrio, piensan que se romperá. Esa es la idea, que puedan sentir un poco de la angustia que sienten los migrantes al abordar el tren" — comparte Leonardo.

La construcción de la "Sala de las Migraciones" duró dos años, desde la concepción del tema hasta la inauguración. Cada septiembre, cuando la universidad realiza la Semana del Migrante, siempre visitan la Sala autoridades y personas de diversos países. De igual manera, la sala está habilitada para el público en general de martes a sábado.

Leonardo comenta que, a pesar de que esta fue la primera exposición en su género en el país, hoy no es la única que existe. “Es ahí donde está el impacto. El Museo Nacional de Antropología Dr. David J. Guzmán replicó la idea e inauguró la exposición "Cultura y Arraigo", siendo la universidad un referente para esta y otras exposiciones" —afirma el museógrafo.
Otro impacto que tuvo el MUA fue en el 2010, cuando adquirió una colección de monedas antiguas y realizó una exposición de la historia de la moneda con la colaboración del Banco Central de Reserva de El Salvador (BCR). Este acercamiento entre las dos instituciones fue muy fructífero, ya que se firmó un convenio para hacer un museo para el banco, el cual se comenzó a trabajar desde junio de 2012 hasta octubre de 2014, año en el que se realizó el montaje final del museo.

Otra influencia positiva de estos hechos es que representantes del Banco Hipotecario visitaron el museo del BCR; y como consecuencia hace poco tiempo acaban de inaugurar el propio. La escuela de Antropología de la Utec asesoró la construcción de dicho museo. "Hemos afectado a tres museos. Somos el referente de algunos de estos museos", menciona, con notable satisfacción, Leonardo.

Entre las proyecciones del MUA para el próximo año está el montaje de la exposición permanente "Costumbres y Cultura Musical", que tratará sobre la tradición musical salvadoreña. Una exposición que se complementa y sirve como una continuación de la "Sala de las Migraciones" es "Referentes Históricos y Cultura Política", que es la exposición permanente que se inauguró en el 2014.

En cuanto a si han pensado hacer una remodelación de la "Sala de las Migraciones", Regalado expone que posiblemente sea dentro de unos años, pues considera que, como en todo, hay un ciclo; y en algún momento algunos temas que toca la Sala se quedarán cortos, tal es el caso de los niños migrantes. Justamente, en ese sentido, la última fotografía que tiene la exposición es la de un padre a punto de cruzar el desierto de la mano con sus dos pequeños hijos. "Ahora la realidad es distinta. Si antes era doloroso pensar que esos pequeños cruzarían el desierto con su padre, ahora lo es mucho más, pues ellos van solos, solos hacia la soledad y crudeza de ese desierto" -concluye Leonardo. 